\title{
Sistem Informasi Pengambilan Kartu Ujian Mahasiswa Plus (Kum+) Berbasis Web
}

\section{INFORMATION SYSTEM FOR WEB-BASED PLUS (KUM +) STUDENT EXAM CARD}

\author{
Ferry Sudarto ${ }^{1}$, Novi Cholisoh ${ }^{2}$, Cheetah Savana Putri ${ }^{3}$ \\ Dosen STMIK Raharja ${ }^{1)}$, Dosen AMIK Raharja ${ }^{2)}$, Mahasiswa STMIK Raharja Jurusan Sistem Informasi ${ }^{3)}$ \\ J1. Jendal Sudirman No. 40 Modern Cikokol 15117 \\ Telp (021) 5529268, 5529692 Fax (021) 5529742 \\ e-mail: ferry.sudarto@raharja.info,novi@raharja.info , cheetah@raharja.info
}

\begin{abstract}
ABSTRAK
Kartu Ujian Mahasiswa adalah salah satu syarat mahasiswa untuk dapat mengikuti Ujian. Pengambilan Kartu Ujian Mahasiswa Plus (KUM+) merupakan sistem pengambilan kartu berbasis web. Namun, di Perguruan Tinggi Negeri maupun Swasta masih banyak yang belum menggunakan Sistem Informasi pengambilan Kartu Ujian Mahasiswa (KUM+) berbasis web, sehingga pengambilan Kartu Ujian Mahasiswa (KUM) masih dilakukan dengan cara manual. Proses pengambilan KUM dengan cara manual dirasa masih kurang efektif karena mahasiswa harus mengantri dalam waktu yang lama dan juga harus datang ke kampus langsung untuk mengisi form pengambilan kartu ujian mahasiswa. Penelitan ini bertujuan untuk menghasilkan Sitem Informasi Pengambilan Kartu Ujian Mahasiswa (KUM+) Berbasis Web. Sehingga dapat memudahkan mahasiswa dalam proses pengambilan kartu ujian mahasiswa tanpa harus datang mengantri di kampus, juga memudahkan bagi pihak kampus dalam menginput jadwal dan tidak lagi mencetak kartu ujian. Sistem ini dirancang menggunakan Bahasa pemprograman Processing Hypertext Programming (PHP). Metode penelitian ini menggunakan metode pengumpulan data melalui wawancara, observasi, studi pustaka dan metode perancangan perangkat lunak menggunakan metode Object Oriented Analysis and Design (OOAD).
\end{abstract}

Kata Kunci - Pengambilan Kartu Ujian Mahasiswa,Web,OOAD,PHP

\section{ABSTRACT}

Student Exam Card is one of the conditions for students to be able to take the Exam. Taking the Plus Student Exam Card $(K U M+)$ is a web-based card retrieval system. However, in many State and Private Universities there are still many who have not used the web-based Student Information Card $(K U M+)$ retrieval system, so that the Student Examination Card (KUM) is still done manually. The process of taking KUM manually is still considered ineffective because students have to queue for a long time and also have to come to the campus directly to fill out the student exam card form. This research aims to produce Information Systems for Taking Web Based Student Exam Cards (KUM +). So that it can facilitate students in the process of taking student exam cards without having to come in line at the campus, it also makes it easier for the campus to input schedules and no longer print exam cards. This system is designed using the Processing Hypertext Programming (PHP) programming language. This research method uses data collection methods through interviews, observations, literature studies and software design methods using the method of Object Oriented Analysis and Design (OOAD).

Keywords - Student Card Acquisition, Web, OOAD, PHP

\section{PENDAHULUAN}

Komputer merupakan salah satu bentuk teknologi informasi yang selalu mengalami perkembangan. Bukti nyata dalam pemanfaatan komputer untuk pencarian data adalah dengan menggunakan layanan internet. Internet adalah salah satu bentuk media komunikasi dan informasi interaktif. Wujud internet adalah jaringan komputer yang terhubung di seluruh dunia. Internet digunakan untuk mengirim informasi antar komputer di seluruh dunia. Sehingga melalui internet kita bisa mengakses dan bertukar informasi secara cepat. ${ }^{[1]}$ Perguruan Tinggi Raharja merupakan institusi pendidikan yang bergerak di bidang teknologi informatika. Sebagai instituisi pendidikan yang memiliki semboyan "Get The Better Future by Computer Science" tentunya manajemen Perguruan Tinggi Raharja selalu berupaya mengembangkan 
sistem pelayanan agar selalu bisa diterapkan menjadi lebih baik lagi dan memiliki manfaat bagi mahasiswa. Pengembangan sistem pelayanan ini ditujukan untuk kenyamanan serta kelancaran dalam proses pengambilan kartu ujian mahasiswa. ${ }^{[2]}$ Penerapan Teknologi Informasi di Perguruan Tinggi pada prinsipnya untuk memudahkan berlangsungnya proses kerja baik dosen, mahasiswa, staff maupun pegawai administrasi dalam hal pengaksesan data dan informasi. STMIK Raharja adalah salah satu Perguruan Tinggi yang belum menggunakan Sistem Informasi pengambilan Kartu Ujian Mahasiswa Plus (KUM+) berbasis web sehingga pengambilan Kartu Ujian Mahasiswa (KUM) dilakukan dengan cara manual atau konvensional.

Kartu ujian mahasiswa (KUM) adalah salah satu layanan yang ada di Perguruan Tinggi baik Negeri maupun Swasta yang memfasilitasi mahasiswa agar dapat mengikuti Ujian Tengah Semester (UTS) dan Ujian Akhir Semester (UAS). Proses pengambilan kartu ujian mahasiswa (KUM) dengan cara konvensional juga dirasa masih kurang efektif karena mahasiswa harus mengantri dalam waktu yang lama dan juga harus datang ke kampus langsung untuk mengisi form pengambilan kartu ujian mahasiswa. Begitu juga karyawan atau staff yang mengurus semua jadwal ujian mahasiswa dan harus selalu mencetak Kartu Ujian Mahasiswa. Sedangkan Form pengambilan kartu ujian mahasiswa yang sudah tidak terpakai akan menyebabkan terjadinya penumpukan digudang. Seiring dengan bertambahnya jumlah mahasiswa di Perguruan Tinggi Raharja menambah jumlah pekerjaan atau semakin meningkatnya tingkat kerepotan yang dialami oleh staff RPU. Dengan adanya Sistem Informasi Pengambilan Kartu Ujian Mahasiswa $(\mathrm{KUM}+)$ Berbasis Web berharap masalah yang terjadi di Perguruan Tinggi dapat teratasi.

\subsection{Tinjauan Pustaka}

Penelitian ini mengenai pengambilan kartu ujian secara online, dalam penelitian ini memerlukan studi pustaka untuk mengetahui menggunakan metode penelitian apa yang akan dilakukan. Diantaranya adalah untuk menghindari pembuatan ulang dan mengidentifikasikan metode yang pernah dilakukan sebelumnya. Beberapa penelitian tersebut adalah sebagai berikut :

1. Penelitian ini dilakukan oleh Muhamad Yusup dari Universitas Budi Luhur Jakarta, pada tahun 2015 yang berjudul "Pengembangan Sistem OJRS+ (Online Jadwal Rencana Studi Plus) sebagai Media Perencanaan Jadwal kuliah". Penelitian ini membahas tentang pengembangan sistem OJRS+ untuk memudahkan proses pelayanan batal tambah jadwal kuliah sehingga menghasilkan data yang cepat dan akurat. ${ }^{[3]}$

2. Penelitian ini dilakukan oleh Luzi Dwi Oktaviana dari STMIK Amikom Purwokerto, pada tahun 2017 yang berjudul "Analisis Penerapan Sistem KRS Online Terhadap Kepuasan Mahasiswa STMIK Amikom Purwokerto Menggunakan Metode UTAUT". Penelitian ini membahas tentang penerapan sistem KRS yang memungkin mahasiswa untuk melihat dan mengolah data-data perkulihan mahasiswa. ${ }^{[4]}$

3. Penelitian ini dilakukan oleh Syahril Hasan dari Politeknik Sains dan Teknologi Wiratama Maluku Utara, pada tahun 2016 yang berjudul "Sistem Informasi Pengisian Kartu Rencana Studi (KRS) Berbasis Web Pada Politeknik Sains Dan Teknologi Wiratama Maluku Utara". Penelitian ini membahas tentang pengisian Kartu Rencana Studi (KRS) untuk memudahkan berlangsungnya proses kerja baik dosen, mahasiswa, maupun pegawai administrasi dalam hal pengaksesan data dan informasi. ${ }^{[5]}$

\subsection{Landasan teori}

2. Ujian

Ujian adalah sistem evaluasi standar pendidikan tinggi dan persamaan mutu antar kelas yang dilakukan oleh kampus. Berdasarkan Undang-undang Republik Indonesia nomor 20 tahun 2003 menyatakan bahwa dalam rangka pengendalian mutu pendidikan secara nasional dilakukan evaluasi sebagai bentuk akuntabilitas penyelenggara 
pendidikan kepada pihak-pihak yang berkepentingan. Pembenahan mutu pendidikan dimulai dengan penentuan standar yang dibuat oleh kampus. ${ }^{[6]}$

3. Web

Website adalah sebuah halaman berisi informasi yang dapat dilihat jaika komputer anda terkoneksi dengan internet. Dengan adanya website, semua orang di dunia bisa mendapatkan dan mengelola informasi dengan berbagai sumber yang tersedia di internet. Website sendiri saat ini bisa memuat berbagai macam media mulai dari teks, gambar, suara, bahkan video. ${ }^{[7]}$

4. Database

Basis data atau Database merupakan sekumpulan data yang memiliki hubungan secara logika dan diatur dengan susunan tertentu serta disimpan dalam media penyimpanan komputer. ${ }^{[8]}$

5. Sistem

Sistem adalah himpunan suatu "benda" nyata atau abstrak yang terdiri atas bagianbagian atau komponen-komponen yang saling berkaitan, berhubungan, berketergantungan, saling mendukung, yang secara keseluruhan bersatu dalam satu kesatuan (unity) untuk mencapai tujuan tertentu secara efisien dan efektif. ${ }^{[9]}$

6. Informasi

Informasi adalah suatu data atau objek yang diproses terlebih dahulu sedemikian rupa sehingga dapat menjadi informasi. ${ }^{[10]}$

7. Sistem Informasi

Sistem informasi merupakan sistem yang dibuat oleh manusia untuk mencapai suatu tujuan yaitu untuk menyajikan informasi dan sekumpulan prosedur organisasi yang pada saat dilaksanakan akan memberikan informasi bagi pengambil keputusan dan atau mengendalikan organisasi. ${ }^{[10]}$

8. Processing Hypertext Programming (PHP)

PHP adalah Bahasa pemprograman scripting server-side yang digunakan untuk memproses data melalui CGI. PHP merupakan Bahasa pemprograman web yang tujuannya untuk menghasilkan skrip yang akan di-generate dalam kode HTML yang merupakan standar web. PHP disebut juga pemrograman Server Side Programming, hal ini dikarenakan seluruh prosesnya dijalankan oleh server. PHP merupakan bahasa pemprograman yang terbuka atau yang dikenal juga dengan open source yaitu pengguna data mengembangkan kode-kode fungsi sesuai dengan kebutuhannya. ${ }^{[11]}$

9. Hypertext Markup Language (HTML)

HTML adalah Bahasa markup untuk memformat konten halaman web. Atau dengan kata lain, Bahasa untuk mengatur bagaimana penampilan dan pemformatan di web. ${ }^{[12]}$

\section{METODE PENELITIAN}

Metode penelitian yang digunakan dalam penelitian ini menggunakan metode pengumpulan data dan metode perancangan. Dalam hal ini objek penelitian yang diambil adalah pengambilan kartu ujian mahasiswa. 
1. Tahap pengumpulan data

1.1 Pengamatan (Observasi)

Pada tahap ini dilakukan dengan mengamati objek yang sedang diteliti dalam hal ini yaitu teknologi informasi berupa sistem informasi yang diterapkan oleh Perguruan tinggi.

1.2 Studi pustaka (Library Research)

Pada tahap ini dilakukan dengan menggunakan buku-buku, penelitian sebelumnya dan jurnal yang berhubungan dengan topik dalam penelitian ini.

1.3 Wawancara

Pada tahap ini dilakukan menggali informasi dan keterangan serta upaya maupun kendala yang dialami dari pihak RPU terkait jalannya sistem yang ada.

2. Tahap Analisa

Pada tahap ini dilakukan Analisa kebutuhan sistem yaitu dengan cara melakukan Analisa terhadap kebutuhan-kebutuhan yang diperlukan untuk membangun sistem yang baru. Digambarkan menggunakan usecase diagram dan sequence diagram.

3. Tahap Rancangan

Pada tahap ini dilakukan dengan mebuat perancangan basis data dan design rancangan pada tahap ini menggunakan metode Object Oriented Analysis and Design (OOAD)

\section{Tahap implementasi}

Pada tahap ini semua rancangan sistem yang dibuat akan diimplementasikan menjadi sebuah program berbasis web yang akan digunakan oleh user yaitu mahasiswa dan admin. Pada tahap ini sistem dirancang menggunakan fasilitas web browser, Bahasa pemprograman PHP dan database MySQL untuk menyimpan data. Sistem KUM+ ini berbasis localhost, dimana sistem hanya dapat diakses melalui jaringan lokal saja.

\section{HASIL DAN PEMBAHASAN}

Sistem Pengambilan Kartu Ujian Mahasiswa Plus (KUM+) dapat membantu mahasiswa dan staff RPU untuk mengakses Kartu Ujian Mahasiswa dengan cepat dimana saja dan kapan saja tanpa perlu lagi datang mengantri di kampus untuk mengambil dan mengisi form. Kartu Ujian, memudahkan Staff RPU menginput data jadwal dan mengedit data tanpa harus mencetak Kartu Ujian Mahasiswa (KUM) dan memudahkan pihak kampus untuk mengontrol dan memantau data jumlah mahasiswa yang aktif pada semester berjalan. Dengan adanya sistem pengambilan Kartu Ujian Mahasiwa Plus (KUM+) ini membuat data dicatat dengan baik, akurasi data tinggi dan pekerjaan menjadi lebih efektif dan efisien.

\subsection{Analisa Kebutuhan Sistem}

Diperlukan gambaran tentang apa saja yang akan diperlukan oleh sistem sebelum merancang sebuah sistem yang baru. Pemahaman kebutuhan yang tepat dapat menghasilkan sebuah sistem yang sesuai dengan kebutuhannya. Oleh karena itu, pendefinisian kebutuhan yang baik akan menjadi faktor kesuksesan dari perancangan sebuah sistem. Analisa kebutuhan sistem akan digambarkan menggunakan Usecase dan Sequence diagram.

Usecase adalah sebuah teknik yang digunakan untuk merekam persyaratan fungsional sebuah sistem. Use Case ini menjelaskan adanya interaksi antara pengguna sistem tersebut dengan sistem itu sendiri, dengan memberikan sebuah narasi tentang bagaimana sistem tersebut digunakan. ${ }^{[13]}$ 


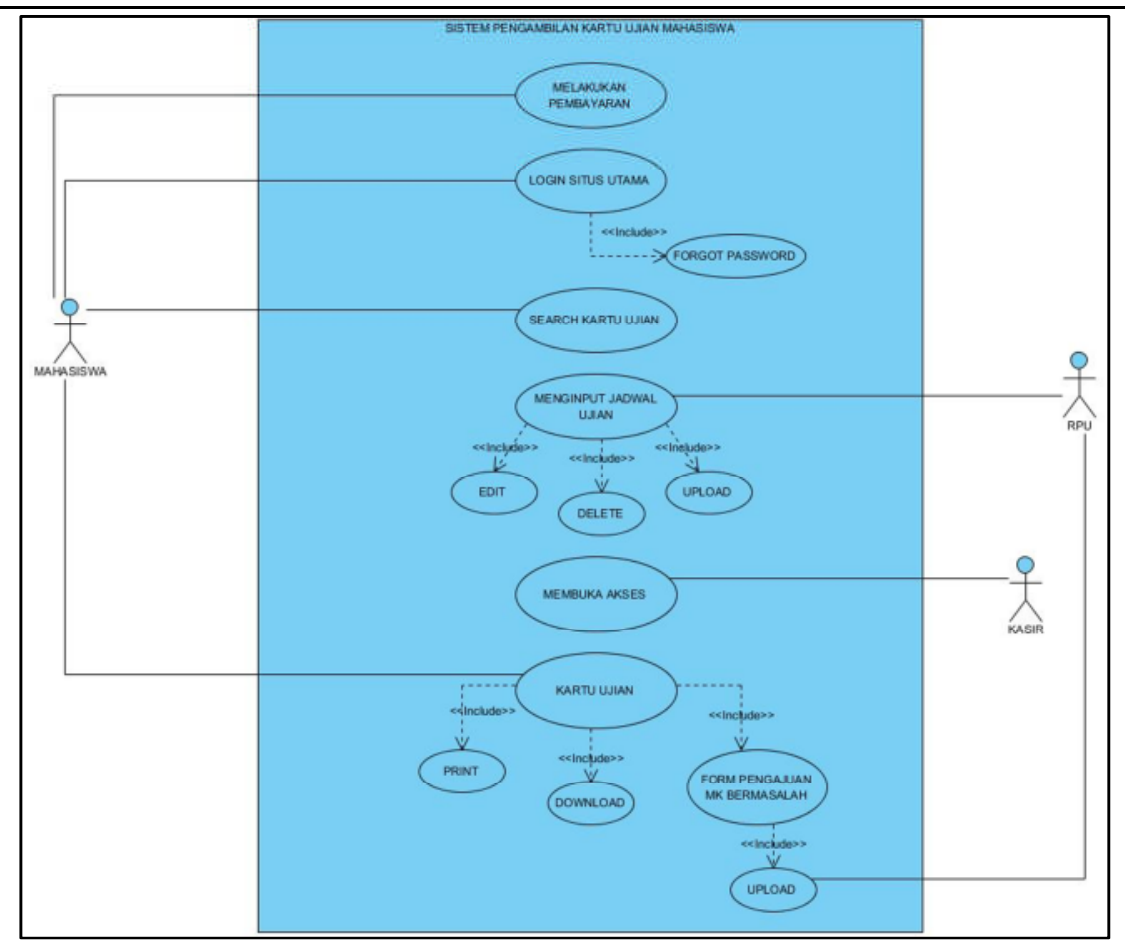

Gambar 1. Usecase Diagram Pengambilan KUM+

Gambar 1. Usecase disini menjelaskan urutan langkah-langkah mahasiswa dalam melakukan pengambilan kartu ujian mahasiswa plus. Begitu juga dengan peran staf RPU dan kasir dalam melakukan penginputan jadwal ujian mahasiwa

Sequence diagram adalah suatu diagram interaksi yang menekankan pada pengaturan waktu dari pesan-pesan. Diagram ini menampilkan sekumpulan peran dan pesan-pesan yang dikirim dan diterima oleh instansi yang memegang peranan tersebut. ${ }^{[14]}$

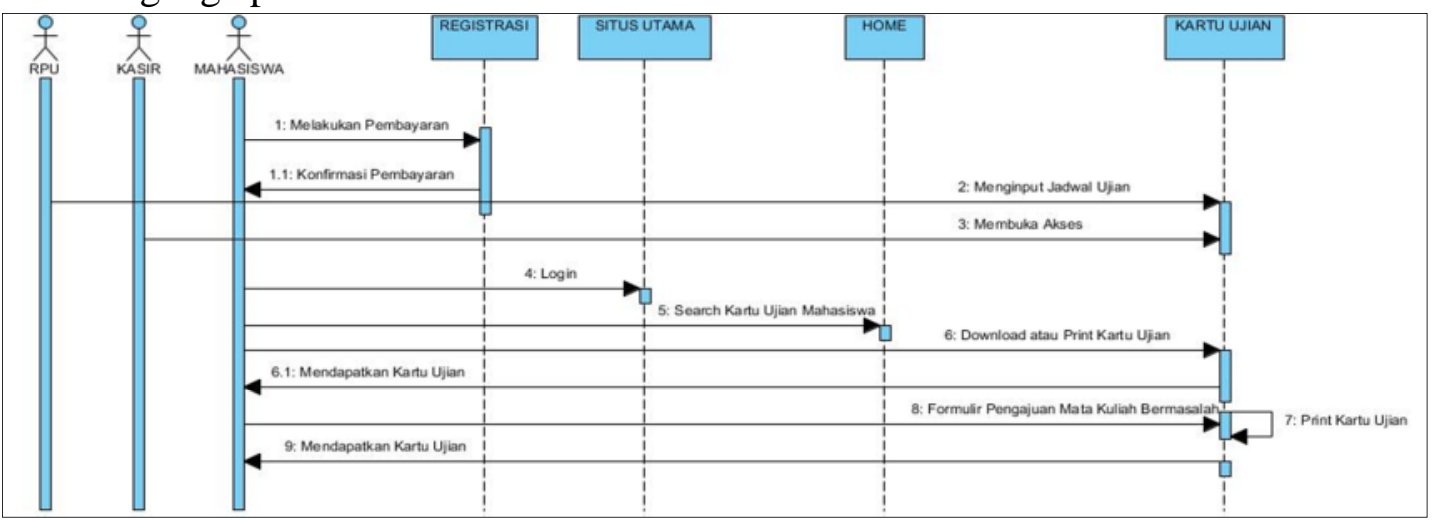

Gambar 2. Sequence diagram Pengambilan KUM+

Hampir serupa dengan usecase diatas, Sequence diagram juga menjelaskan langkah-langkah yang dilakukan oleh mahasiswa dan peran serta staff RPU dan kasir.

\subsection{Rancangan Perangkat Lunak}

Pada tahap Analisa perangkat lunak ini menggunakan metode Object-Oriented Analysis and Design (OOAD) yaitu metode analisis yang memeriksa kebutuhan - kebutuhan dari sudut pandang kelas - kelas dan objek yang ditemui didalam ruang lingkup permasalahan 
yang mengarahkan arsitektur software yang didasarkan pada manipulasi objek - objek sistem atau subsistem. Metode OOAD ini merupakan cara baru dalam memikirkan suatu permasalahan dengan menggunakan model yang dibuat menurut konsep sekitar dunia nyata. Dasar pembuatan adalah objek, yang merupakan kombinasi anatara struktur data dan perilaku dalam satu entitas. ${ }^{[15]}$

\subsection{Implementasi}

Pada tahap implementasi ini merupakan penerapan pada sistem pengambilan kartu ujian. Prototype yang telah di buat menggunakan HTML setelah di uji ternyata running selanjutnya akan diimplementasikan menggunakan web sebagai media untuk menyampaiakan informasi seputar kartu ujian mahasiswa baik itu jadwal ujain tengah semester (UTS), jadwal ujian akhir semester ( UAS) dan jadwal ujian semester pendek (SP) selain mudah untuk di akses juga mudah dipahami. ${ }^{[16]}$

Kartu ujian mahasiswa di akses di http://sisplus.raharja.ac.id/login berhasil di tampilkan berikut tampilannya:

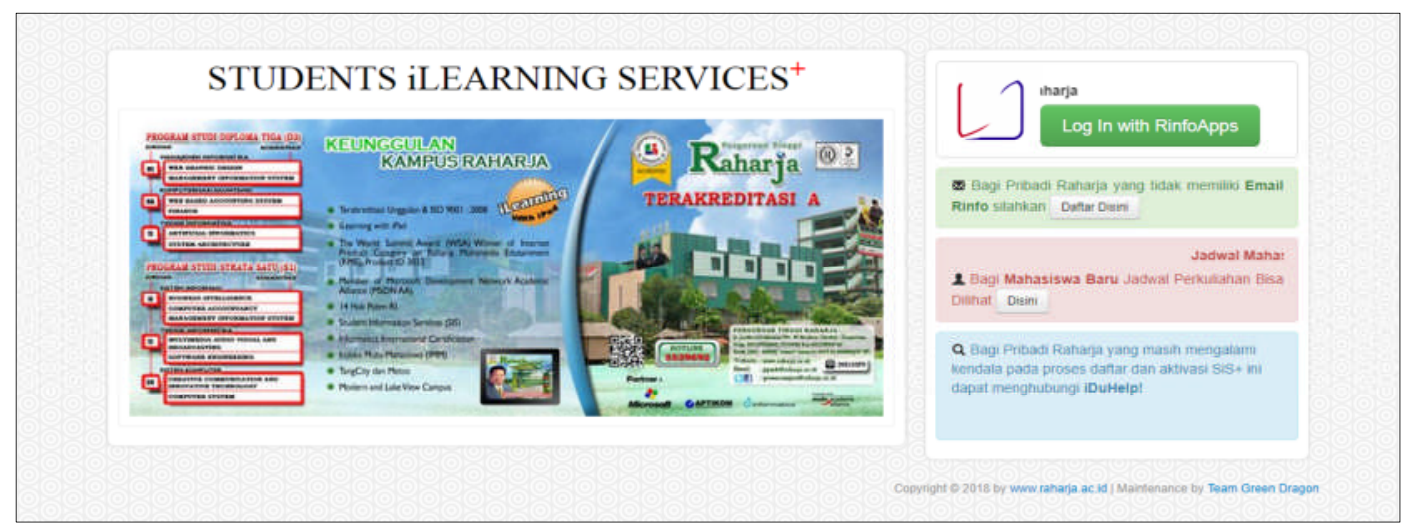

Gambar 3. Tampilan Login Situs Utama

Dalam mengakses pengambilan kartu ujian, mahasiswa diharuskan terlebih dahulu masuk ke sistus utama. Disini mahasiswa diharuskan memasukan email dan mengisi password agar bisa masuk ke situs utama.

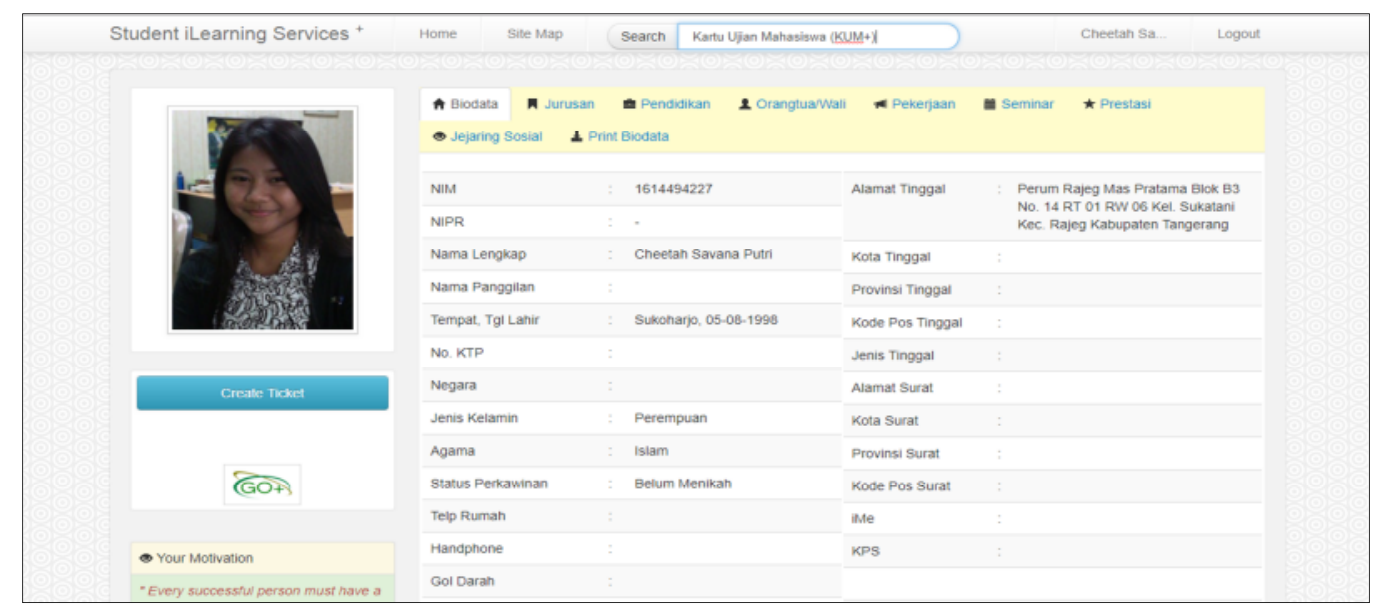

Gambar 4. Tampilan Home

Setelah berhasil login ke dalam situs utama, muncul tampilan home yang berisikan biodata mahasiswa dan juga berbagai menu salah satunya menu pencarian yang akan digunakan mahasiswa untuk mencari kartu ujian mahasiswa plus. 


\section{ololpsi!}

SORRY !!!

Gambar 5. Tampilan Akses Terblokir

Mahasiswa yang belum melakukan pembayaran atau pelunasan yang disyaratkan akan memperoleh tampilan seperti diatas, itu berarti mahasiswa diharuskan untuk melakukan pembayaran atau pelunasan yang disyaratkan tersebut. Setelah terkonfirmasi pembayaran dari mahasiswa, maka mahasiswa baru bisa mengakses halaman kartu ujian mahasiswa plus seperti contoh dalam gambar 6.

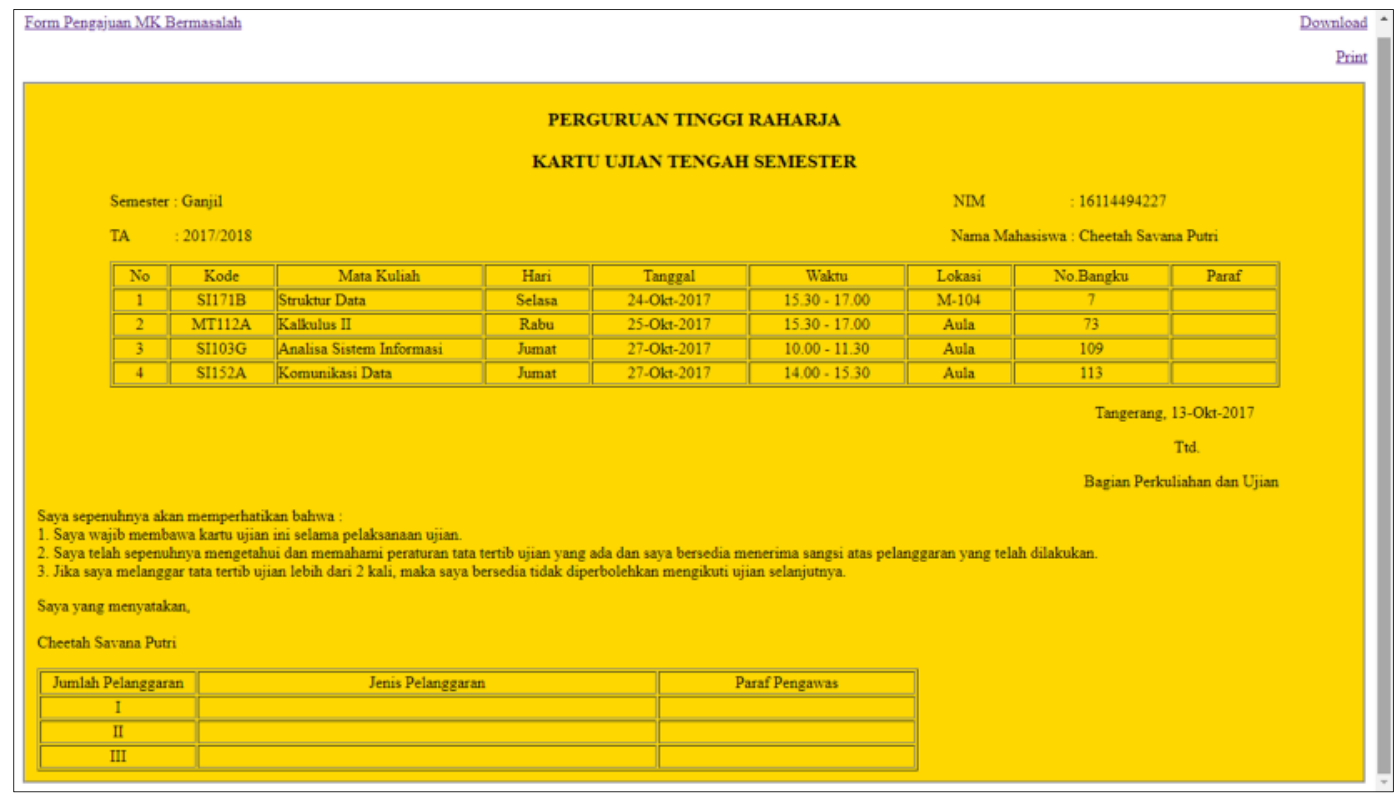

Gambar 6. Tampilan Kartu UTS

Gambar 6 Merupakan contoh interface kartu UTS, UAS dan SP. Gambar ini memperlihatkan kartu ujian mahasiswa yang akan dicetak, halaman tersebut berisi tiga pilihan diantaranya download, print dan form pengajuan mata kuliah yang bermasalah, apabila mahasiswa tidak ada masalah dengan jadwal ujian maka mahasiswa bisa langsung mendownload atau memprint kartu ujian. Namun, jika mahasiswa mendapat masalah dengan jadwal ujian maka mahasiswa dapat memilih form pengajuan mata kuliah yang ditujukan ke bagian Adm Dosen. 


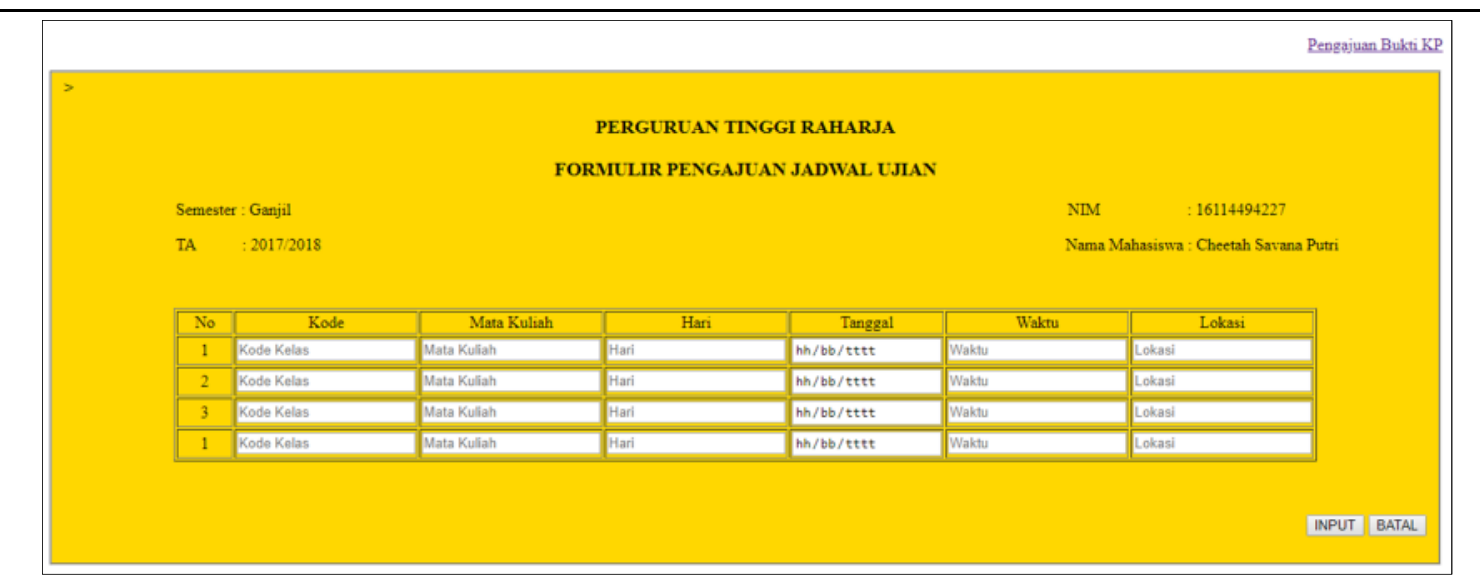

Gambar 7. Tampilan form pengajuan MK bermasalah (UTS)

Dalam form tersebut mahasiswa dapat mengisi mata kuliah yang bermasalah. Mahasiswa dapat langsung menginput jadwal yang sudah diisi dan dapat membatalkan jadwal yang sedang diisi, untuk jadwal yang telah diinput atau diupload akan langsung diproses oleh bagian Adm Dosen.

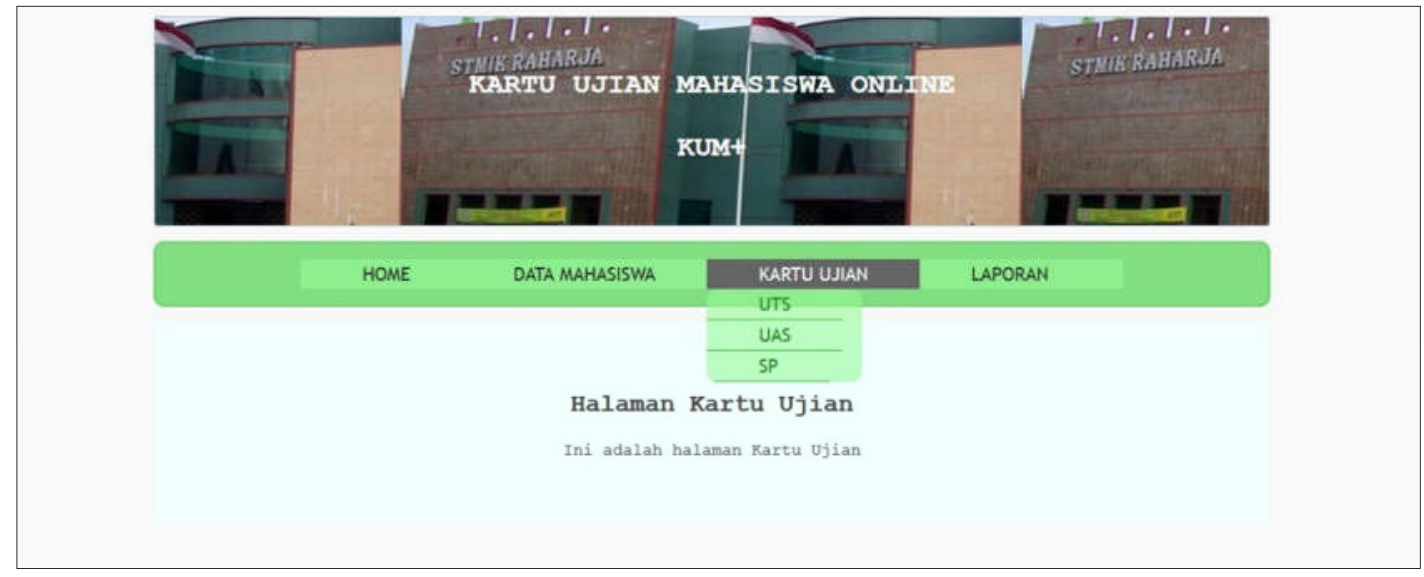

Gambar 8. Tampilan Menu Admin

Pada tampilan menu admin, terdapat 4 menu utama salah satunya adalah menu data mahasiswa dimana seorang admin dapat memantau atau melihat mahasiswa yang berhak dan tidak untuk ikut ujian dan terdapat menu kartu ujian dimana pada menu tampilan kartu ujian seorang admin dapat menginput jadwal ujian sesuai dengan jadwal ujian yang sedang berlangsung .

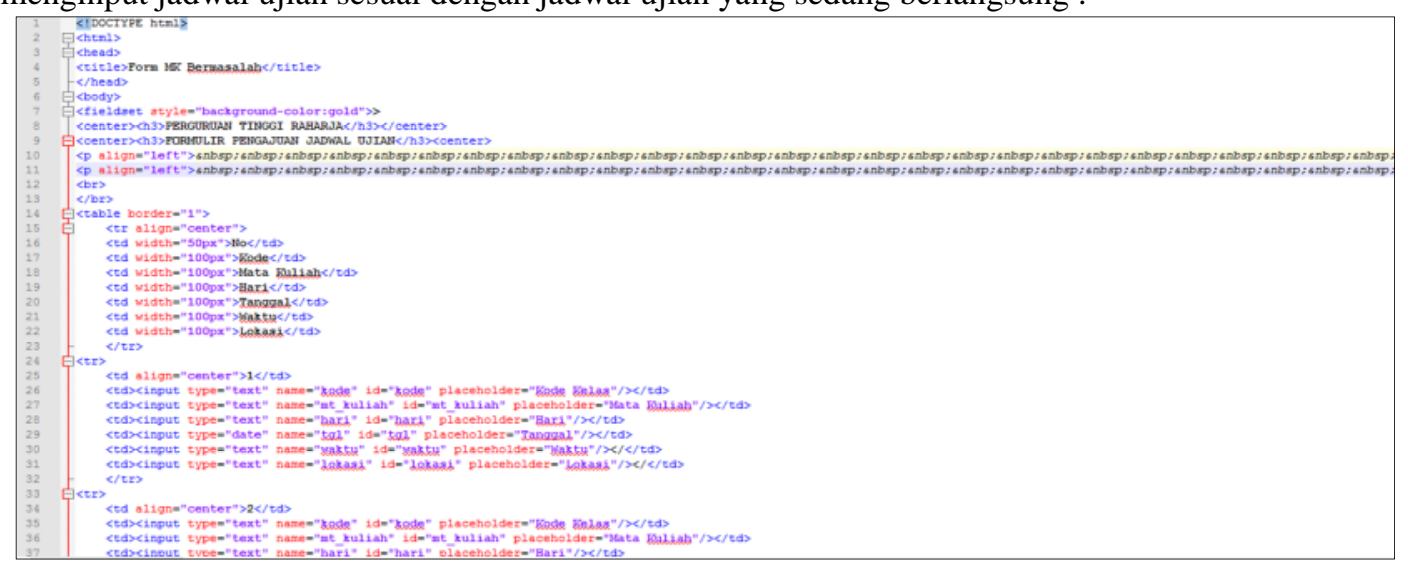

Gambar 9. Coding KUM+ 
Pada gambar diatas merupakan kodingan untuk tampilan kartu ujian mahasiswa, kodingan tersebut dibuat menggunakan HTML dan CSS.

\section{KESIMPULAN}

Berdasarkan uraian pada bab-bab sebelumnya dan juga berdasarkan hasil pengamatan penulis selama melakukan observasi, maka dapat diambil beberapa kesimpulan diantaranya :

1. Dengan dibuatnya sistem informasi pengambilan kartu ujian mahasiswa plus (KUM+) ini dapat memudahkan mahasiswa dalam mengakses jadwal ujian yang dapat dilakukan dimana saja dan kapan saja, mahasiswa tidak harus lagi datang kekampus untuk mengambil kartu ujian, mahasiswa tidak harus lagi mengantri dan mahasiswa tidak harus lagi mengisi form pengambilan kartu ujian.

2. Dengan dibuatnya sistem informasi pengambilan kartu ujian mahasiswa plus (KUM+) ini dapat memudahkan staff RPU dalam penginputan jadwal ujian yang secara online, staff RPU dapat menangani dan melayani mahasiswa yang bermasalah dengan jadwal ujian secara online dan staff RPU tidak lagi mencetak kartu ujian mahasiswa dan formulir pengambilan kartu ujian.

3. Dengan dibuatnya sistem informasi pengambilan kartu ujian mahasiswa plus (KUM+) ini dapat meminimalisirkan pengeluaran kampus karena tidak pihak kampus tidak lagi mencetak kartu ujian dan mencetak form pengambilan kartu ujian.

Dengan adanya sistem pengambilan kartu ujian mahasiswa plus (KUM+) diharapkan mampu memberikan mutu pelayanan yang baik untuk mahasiswa dan staff RPU dalam pengaksesan jadwal dan penginputan jadwal

\section{SARAN}

Saran yang dapat disampaikan oleh penulis adalah agar penelitian berikutnya dapat mengembangkan sistem informasi pengambilan kartu ujian mahasiswa plus (KUM+) menjadi lebih baik lagi. Saran yang digunakan sebagai bahan pertimbangannya, terdiri dari 3 (tiga) diantaranya :

1. Supaya sistem informasi pengambilan kartu ujian mahasiswa plus (KUM+) harus disempurnakan melalui konsep dan strategi pengembangan yang baru, sehingga informasi dapat terealisasi dengan baik.

2. Perlu adanya pengembangan dalam sistem pengambilan kartu ujian mahasiswa di Perguruan Tinggi Raharja dari manual menjadi yang berbasis web sehingga dapat meminimalisir kesalahan dan juga mempercepat dalam proses pembuatan jadwal dan pengambilan kartu ujian .

3. Sistem pengambilan kartu mahasiswa plus (KUM+) alangkah baiknya dapat diterapkan di setiap perguruan tinggi, karena sangat membantu mahasiswa, staff RPU dan juga dapat meningkatkan pelayanan perguruan tinggi mengenai pengambilan kartu ujian mahasiswa .

\section{DAFTAR PUSTAKA}

[1] Krisianto, A. (2014). Internet Untuk Pemula. Elex Media Komputindo.

[2] Rahardja, U., Aini, Q., \& Thalia, M. B. (2018). Penerapan Menu Konfirmasi Pembayaran Online Berbasis Yii pada Perguruan Tinggi. Creative Information Technology Journal, 4(3), 174-185. 
[3] Yusup, M., Warsito, A. B., \& Apriyani, N. (2016). PENGEMBANGAN SISTEM OJRS+ (ONLINE JADWAL RENCANA STUDI PLUS) SEBAGAI MEDIA PERENCANAAN JADWAL KULIAH. CCIT Journal, 9(2), 118-134.

[4] Oktaviana, L. D., Rifa'i, Z., \& Utami, K. Analisis Penerapan Sistem KRS Online Terhadap Kepuasan Mahasiswa STMIK Amikom Purwokerto Menggunakan Metode UTAUT.

[5] Sains, S. H. P., \& Utara, T. W. M. (2017). Sistem Informasi Pengisian Kartu Rencana Studi (KRS) Berbasis Web Pada Politeknik Sains Dan Teknologi Wiratama Maluku Utara. IJNSIndonesian Jornal on Networking and Security, 6(1).

[6] Rahardja, U., Yusup, M., \& Aini, Q. (2014). Aplikasi Campus Learning System iOU (integrated Online Ujian) Dalam Mendukung Kegiatan iLearning Education (iDu) Pada Perguruan Tinggi. CCIT Journal, 7(3), 368-383.

[7] Komputer, W. (2010). Membangun Website Tanpa Modal. Penerbit Andi.

[8] Komputer, W. (2010). ShortCourse Series: SQL Server 2008 Express. Penerbit Andi.

[9] Ladjamudin, A. B. B. (2005). Analisis dan Design Sistem Informasi, Yogyakarta: Graha Ilmu. Commerce dan SMS. Jakarta: PT Elex Media Komputindo.

[10] Rusdiana, A., Rusdiana, A., Irfan, M., \& Irfan, M. (2014). Sistem informasi manajemen.

[11] Winarno, E., \& Zaki, A. (2013). Buku Sakti Pemrograman PHP. Jakarta: PT Elex Media Komputindo.

[12] Jefferly, H. (2013). Praktis dan mudah mendesain website, langkah-langkah mudah membuat web profesional dengan mudah dan praktis.

[13] Fowler, M. (2005). UML Distilled edisi 3 panduan singkat bahasa pemodelan objek standar. Yogyakarta: Andi.

[14] Booch, G. (2005). The unified modeling language user guide. Pearson Education India.

[15] Krisianto, A. (2014). Internet Untuk Pemula. Elex Media Komputindo.

[16] Rahardja, U., Aini, Q., \& Enay, N. (2017). Optimalisasi Dashboard pada Sistem Penilaian Sebagai Media Informasi di Perguruan Tinggi. SISFOTENIKA, 7(2), 167-176. 